\title{
O MISTÉRIO DOS OBJETOS
}

Prof. Dr. Cláudia Regina Plens ${ }^{1}$

Um lugar santo repleto de parafernália religiosa, sendo algumas das relíquias uma coroa, brincos e um colar! Assim Howard Carson interpreta o significado de objetos mágico-religiosos como o assento de uma privada, escovas de dente e mangueira da banheira localizados em um banheiro de um motel! Quem não riu com as interpretações alucinantes do arqueólogo amador do ano 4022 que encontra as ruínas de um antigo motel do século XX, na obra de David Macaulay Motel dos Mistérios?

Este clássico dos anos 1970 satiriza as interpretações de alguns arqueólogos amadores que sem técnica, metodologia ou teoria adequadas tentam atribuir funções a objetos cujos significados se perderam ao longo do curso da história.

No entanto, na prática, as interpretações da cultura material nem sempre são tão esquizofrênicas. Tampouco os arqueólogos dependem da sorte para localizar "bons" achados arqueológicos para poder inferir o comportamento humano a partir da cultura material. $\mathrm{O}$ treinamento do arqueólogo em teoria, método e técnicas na academia, além da responsabilidade e ética do pesquisador, são essenciais para a apuração e o refinamento das pesquisas arqueológicas.

Por esta razão é importante que todo o público que se interesse por essa área do conhecimento compreenda a partir de que dados a história está sendo contada por meio do objeto, pois há elementos chaves que podem distinguir a boa pesquisa arqueológica do charlatanismo que geralmente vem fundamentado em um discurso dramático, com respostas bastante simples e sem dados que respaldem suas respostas. Pior ainda, nestes discursos melodramáticos, todo o esforço dos nossos antepassados para se adaptarem e sobreviverem às forças da natureza construindo bens materiais que os protegessem e de acordo com seus conceitos de vida é geralmente atribuído a extraterrestres.

Embora estes discursos repletos de enigmas sejam à primeira vista fascinantes, não é com menos mistério e magia que a ciência trata de suas questões, porém é com respostas mais elaboradas, a partir de uma variada gama de dados, que se visa compreender o comportamento humano por meio da cultura material.

\footnotetext{
${ }^{1}$ Laboratório de Estudos Arqueológicos (LEA), Universidade Federal de São Paulo (UNIFESP/campus Guarulhos).
} 


\section{Revista de Arqueologia Pública}

É neste intuito que a disciplina Fundamentos da Prática Arqueológica do curso da UNISA se propôs a ensinar os fundamentos básicos da arqueologia para os interessados em futuramente ingressar na carreira de arqueólogo e, também, para dar ferramentas aos demais interessados na arqueologia discernir entre a ciência arqueológica e meras especulações a que somos expostos todos os dias.

Muitos dos alunos que não seguiram na carreira arqueológica após o curso lato sensu da UNISA são professores que estão replicando o saber e novos modos de pensar em suas salas de aula. É neste âmbito, como multiplicador de conhecimento, que o curso visou trabalhar, onde o diálogo, as trocas de ideias e impressões foram expostas e debatidas. A Prof. Dr. Carolina Kesser Barcellos Dias brilhantemente abraçou este conceito e formulou um exercício onde os artefatos já conhecidos destes pesquisadores poderiam ser analisados de forma empírica e, portanto, científica.

Embora os objetos analisados fossem de perfeito conhecimento e até íntimo dos pesquisadores, não foi com menos dificuldade que a aplicação de meios empíricos de se levantar dados que mostrassem ao leitor os significados dos objetos e o comportamento humano por detrás da cultura material foi feita.

A arqueologia está no imaginário de grande parte da população, Agatha Christie e Indiana Jones em muito contribuíram para o senso de mistério, aventura e magia na prática arqueológica. Muitos amantes de arqueologia, no entanto, tendem a se decepcionar quando veem a arqueologia menos glamorosa e brilhante a partir de suas concepções preconcebidas. Dinossauros? Não, a arqueologia não estuda os dinossauros e, sim, a paleontologia. A arqueologia é o estudo do comportamento humano por meio da cultura material. Como há um grande leque temporal que separa a humanidade dos dinossauros, são outros profissionais incumbidos do estudo das grandes criaturas.

Tampouco a arqueologia se encarrega apenas do estudo de estruturas grandiosas e exuberantes e de grande valor comercial. Pequenas estruturas ou pequenos artefatos, fragmentos de artefatos, os famosos caquinhos, cacarecos, trecos ou mesmo o lixo que descartamos são passíveis de estudo para interpretação do comportamento humano, tal como nos mostraram todos os autores desta obra.

Nem sempre esses vestígios estão sob a terra, envolvidos no mistério das profundezas, esperando para serem revelados pelo arqueólogo que detém, entre outras técnicas, a técnica apropriada para a escavação. Esses objetos nos cercam, estão em todos os lugares, na cidade em que passamos todos os dias, no nosso bairro, em frente aos nossos portões, ou mesmo no interior de nossas casas. Todos esses objetos guardam uma história de vida, de significados, bastando um olhar apropriado sob a ótica de técnicas, métodos e teoria adequados para enxergar a história da vida das pessoas por meio destes artefatos.

Essa arqueologia, ao alcance de todos, pode também ser chamada de estudo da cultura material. Independente da uma grande especialização por parte do pesquisador em temas específicos da arqueologia, o estudo da cultura material pode ser acessível por meio de questões simples, mas 


\section{Revista de Arqueologia Pública}

não sem o rigor e a complexidade analítica na resposta. É disso que se trata o estudo da cultura material.

As perguntas simples às quais os arqueólogos esperam respostas complexas e rigorosamente analisadas se baseiam nas decisões tomadas por pessoas e as consequências materiais resultadas delas, sendo, para tanto, necessário compreender a história de vida do objeto. Por exemplo, qual a matéria-prima do artefato, onde foi obtida a matéria-prima, onde e com qual intuito ele foi confeccionado, quais as técnicas aplicadas na sua confecção, como e por quem o artefato foi utilizado, por que e como o material deixou de ser utilizado e, por fim, como ele foi abandonado ou descartado? As respostas a essa bateria de perguntas são suficientes para um grande conhecimento sobre as pessoas por detrás dos objetos.

Mas as questões são muitas, e um pouco mais adiante, devemos nos perguntar sobre os processos de formação do artefato, ou seja, se as marcas localizadas em uma estrutura ou artefato se devem a causas naturais ou culturais. Há mais do que uma explicação possível? Onde estão os dados que nos apontem em direção a uma resposta mais plausível? Há tipos diferentes de preservação? Algum artefato ou estrutura parece ter sobrevivido mais do que outra? Qual a razão de alguns artefatos terem sido preservados e outros não? Talvez fatores naturais possam ter atuado na preservação de alguns artefatos em detrimento de outros, mas em outros casos, a escolha humana pode ter atuado na preservação de um elemento em especial; neste caso, qual a razão?

O objeto por si só pode indicar uma série de dados, mas a relação dos objetos entre si também é muito importante, é o que nós arqueólogos costumamos chamar de contexto arqueológico. Qual a relação ou associação de um determinado objeto com outros ao seu redor? Em alguns casos temos o contexto vertical em camadas arqueológicas, onde alguns objetos tiveram relação atemporal com outros, no entanto, em alguns casos, o contexto horizontal nos indica a relação de objetos que foram ou estão sendo utilizados concomitantemente. Quais as relações mais próximas e mais distantes? E quais são os tipos de relações entre si?

Para a compreensão do contexto do artefato, um dos mais básicos métodos é a classificação dos objetos, seja por sua matéria-prima, seja pela sua função, sua cor etc. Há uma infinidade de possibilidade de classificação por meio da qual a mente humana é capaz de entender a relação existente entre os objetos. Cabe ao pesquisador estipular quais os atributos da sua classificação que o levam aos dados desejados para sua análise.

Todos os autores desta obra obrigatoriamente desenvolveram diferentes tipos de classificação: Cássia Aparecida Guimarães e Gladys Mary Santos Sales recorreram, sobretudo, à tipologia e ao contexto vertical, a sobreposição das "camadas arqueológicas" ou a sobreposição dos objetos, a ordem em que os objetos foram sendo descobertos ou em que foram colocadas, para distinguir o que veio antes e o que veio depois. Cinthya K. Ramos e Layla Chaves Lucena também classificaram seus objetos a partir de uma classificação espacial, quais itens compõem nichos específicos, tipo e cor dos objetos. Marcos Rogério da Silva Moreira optou pela classificação da matéria-prima dos objetos analisados. Já Maurício Rodrigues de Resende recorreu à classificação por funcionalidade de seus

\begin{tabular}{|l|l|l|l|l|l|l|}
\hline (C) Rev. Arqueologia Pública & Campinas, SP & v. 10 & n. 1 & p. 109-113 & MAR. 2016 & ISSN 2237-8294 \\
\hline
\end{tabular}




\section{Revista de Arqueologia Pública}

artefatos. Wagner Magalhães utiliza o cruzamento de diferentes parâmetros de classificação para obter resultados que lhe permitisse uma discussão maior.

Somente a partir dessa etapa de classificação é possível entender que a pesquisa do arqueólogo, ou do pesquisador da cultura material, não se resume às grandes descobertas de campo, mas, sobretudo a um árduo trabalho de documentação, em campo e laboratório, para que o trabalho de classificação, espacialidade, enfim, todo o contexto arqueológico, seja possível de ser averiguado e analisado a posteriori. A localização do artefato é só o início de um longo percurso de pesquisa arqueológica.

Quanto maior for a quantidade de técnicas, métodos e teorias da arqueologia que o pesquisador detiver conhecimento, maior será sua capacidade de fazer "grandes achados" arqueológicos. Por um lado, o conhecimento de uma ampla gama e diversidade de temas arqueológicos é imprescindível para o pesquisador poder compreender a relação que diferentes materiais mantêm entre si. Por outro, a especialização, ou seja, o conhecimento aprofundado em alguns materiais e temas, é o caminho natural daqueles que mais e mais estudam determinados artefatos ou sítios arqueológicos, podendo alcançar novas respostas acerca do objeto.

Uma vez que o arqueólogo alcança dados suficientes para responder satisfatoriamente suas questões, há, ainda, mais uma importantíssima etapa a ser cumprida para a finalização de seu trabalho, a publicação. Como esta obra expõe e todos os autores deixaram claro em seus artigos, estudos que não são expostos e abertos para um diálogo com o público não têm razão de ser. Por essa razão a publicação de dados, em diferentes linguagens, para diferentes públicos, é necessária. Pois é a partir de debates, críticas e novos estudos de reinterpretação de dados que a ciência cresce. $\mathrm{Na}$ ciência não há uma verdade absoluta, mas o conhecimento que engrandece com o tempo e com a maior quantidade de pessoas debatendo e agregando novos dados.

Os objetos, cacarecos, lixo e artefatos nos cercam e fazem parte da realidade de todas as pessoas, de todas as idades, em todo o globo. O modo como as culturas lidam com os objetos é, contudo, diferente. É nessa diferença de relação entre a humanidade e objetos que recai a magia, o mistério dos objetos. Por que as pessoas confeccionam e respondem à cultura material e ao ambiente de diferentes maneiras? As respostas a esse grande enigma está na materialidade. O estudo científico da cultura material que nos cerca nos possibilita entrar neste mundo de mistério e magia dos objetos. Os artigos presentes nesta obra ampliam nossa visão para dentro da nossa própria casa que acreditávamos que já nos era tão íntima. A partir de agora, olhar os objetos que nos cercam será diferente. Pensar na relação que os objetos mantêm entre si, colocados lá consciente ou inconscientemente por nós mesmos, pode trazer respostas para o nosso próprio comportamento e a história de vida dos objetos.

\section{AGRADECIMENTOS}

Não poderia deixar de agradecer aqui primeiramente o Prof. Dr. Álvaro Allegrette que atenciosamente me convidou para lecionar sua disciplina na UNISA. Posteriormente, O Prof. Dr.

\begin{tabular}{|l|l|l|l|l|l|l|}
\hline (C) Rev. Arqueologia Pública & Campinas, SP & v. 10 & n. 1 & p. 109-113 & MAR. 2016 & ISSN 2237-8294 \\
\hline
\end{tabular}




\section{ARTIGO}

\section{Revista de Arqueologia Pública}

Vagner Carvalheiro Porto quem me recebeu com muito profissionalismo e bastante receptivo, culminando em uma parceria de pesquisa que se estende até hoje. À própria UNISA se deve um agradecimento por ter recebido este curso tão importante para a formação de uma nova consciência social. Esse caráter inovador da UNISA a destaca dentre muitas outras universidades brasileiras que ainda não estão abertas a cursos semelhantes. Por fim, mas não menos importante, a Prof. Dr. Carolina Kesser Barcellos Dias por ter aceitado me substituir em uma disciplina que para mim foi tão cara, minha primeira experiência como docente, e por ter me convidado para participar desta obra de significante iniciativa. A todos, meu sincero muito obrigada pela oportunidade de participar com vocês nesta trajetória na UNISA. 